\title{
Energy Storage in Grid-Connected Photovoltaic Plants
}

\author{
Rosario Carbone \\ University "Mediterranea" of Reggio Calabria \\ Italy
}

\section{Introduction}

Nowadays, photovoltaic (PV) plants are receiving a very great attention due to their intrinsic ability to directly transform solar energy in electrical energy.

Nevertheless, electricity generated from photovoltaic plants can rarely provide immediate response to load demand, as these sources do not deliver a regular supply immediately compatible with consumption needs.

In stand-alone PV plants, energy storage (typically based on electrochemical batteries), together with the help of additional generation systems (such as those powered by fuel engines), is on the basis of regularization of PV generation and of full satisfaction of load consumptions.

In grid-connected PV plants - theoretically - energy storage is not necessary or useful, due to the availability of the distribution grid that should work as an ideal container of the electrical energy (theoretically, it can work both as an ideal generator and, also, as an ideal load). However, in this last years, an important attention has been devoted to the use of energy storage also in grid-connected PV plants, with the main aim of overcoming some important power quality problems of real distribution grids and for making PV plants more and more useful and attractive.

In fact, avoiding more extensive details, energy-storage seems able to improve reliability, availability and energy generation efficiency of grid-connected PV plants, still poor because a lot of problems including: the high variability of solar energy availability, the high energy generation losses (i.e. caused by non-uniform solar irradiation conditions of PV fields) and the disturbances introduced by non-linear behaviour of power electronic apparatus (widely, PWM inverters) currently utilized for interconnecting PV plants with distribution grids.

Most of these recent studies are substantially focused on sizing, operating and analysing of electrochemical energy storage systems to be used as an "energy buffer" for reducing, within acceptable limits, aforementioned problems and for improving some important grid auxiliary services as:

- load balancing and peak shaving;

- compensation of disturbances (outages, voltage drops and dips, PF correction, ...);

- economic optimization of generated/consumed energy flows;

- optimal integration among different kind of renewable energy resources (PV, wind, fuel-cells, ...). 
Aforementioned ancillary services are undoubtedly of strategic importance for future largescale development and diffusion of grid-connected PV plants.

However, as evidenced in current researches, they are based on centralized and conspicuous electrochemical amount of batteries (based on different technologies) whose potentials, in the opinion of the author, can be further improved [Denholm et al., 2007; Lo et al., 2005; Lu and Shahidehpour, 2005].

Having in mind the objective to obtain, in addition to previously mentioned ancillary services, the important goal of improving reliability, availability and electrical energy generation capability of grid-connected PV plants (under assigned solar irradiation conditions), the new idea that will be fully analysed in this work is that batteries can be used in a new and more effective "distributed manner".

In this new context, batteries, with a reduced whole capacity value, can be utilized as distributed passive maximum power point trackers (MPPT) able of maximizing the amount of energy generated by grid-connected PV plants in presence of non-uniform shadowing (partial shadowing) effects on PV fields, as an alternative to the more expensive and complex active MPPTs [Carbone, 2009].

In the following, after introducing the potential benefits of the electricity storage in distribution grids (section 2) and after recalling currently utilized methodologies for improving power generation of grid-connected PV plants (section 3), the proposal of utilizing the energy storage in grid-connected PV plants, operated by using batteries in a distributed manner, is fully described (section 4) from the theoretical point of view.

In section 5, the effectiveness and the usefulness of the propped methodology is fully investigated, by means of a lot of experimental tests.

In section 5.1, experimental tests are performed and discussed by referring to a small-scale prototype of about $20 \mathrm{Wp}$ of power, constituted by $4 \mathrm{PV}$ small-panels, each of about $5 \mathrm{Wp}$, together with $8 \mathrm{NiCd}$ rechargeable batteries, each with $1.2 \mathrm{~V}$ and $800 \mathrm{mAh}$ of capacity.

In section 5.2, experimental tests are performed and discussed by referring to a physically realized $18 \mathrm{kWp}$ PV plant, connected to the LV distribution grid and owned by the B\&T Solar Energy Division Company, on Lazzaro (RC), Italy. The PV plant is realized by means of 90 PV modules with $200 \mathrm{Wp}$ and with an open circuit voltage of about $40 \mathrm{~V}$; PV modules are grouped in 3 PV sub-fields (with 30 modules and $6 \mathrm{kWp}$ ) connected to the grid by means of three different single-phase PWM inverters. Because of each inverter has two separate DC-inputs, with separate DC-DC boost-converter operating the MPPT function, each subfield is realized with 2 different groups of 15 series-connected PV modules. For our experimental tests and measurements, only one group of 15 series-connected PV modules (3 $\mathrm{kWp}$ ) of a single-phase PV sub-field has been considered; furthermore, because of the temporarily limited availability of batteries, only 9 modules of the 15 series-connected PV modules have been experimented with (and without) batteries. In particular, a group of 3 series-connected lead-acid batteries, each with $12 \mathrm{~V}$ and $10 \mathrm{Ah}$ of capacity, are connected in parallel to each group of 3 parallel-connected PV modules.

Finally, in section 6, some perspectives on the possibility of designing and developing single AC PV modules, with on board a distributed energy storage system, for direct connection with low voltage distribution grids and characterized by high availability and high quality of the output AC voltage waveform, are also developed. 


\section{Advantages of energy storage in electricity distribution grids}

In recent years, a lot of papers have been published in the specialised literature to discuss about the usefulness of energy storage systems in modern distribution systems, especially in presence of distributed generation systems from renewable (PV plants, wind farms, fuel cells, high-efficiency co-generation systems, ...).

Regardless of their type and their technology (batteries, super-capacitors, super-magnetics, flywheels, pumped-hydro, compressed air, hydrogen, ...), the main outcome of all these studies is that energy storage systems are on the basis of the achievement of very important and valuable ancillary services, able to significantly improve reliability, availability and power quality of modern distribution grids.

A first basic concept is that the energy storage adds value to distributed generation plants from renewable by making them predictable.

That said, one of the most critical problems of distribution grids is, undoubtedly, that of satisfying the peaks of the load demand. The use of one ore more of the aforementioned energy storage systems can effectively compensate for load variations, so making possible to operate transmission, sub-transmission, and distribution networks with lighter designs, that is to say, energy storage can be used instead of more complex, expensive and inefficient needed solutions (over-sizing of base-load generation units, peaking generation units based on combustion turbines, ...).

Energy storage facilitates the active and reactive power flow control for distribution grid voltage regulation.

Energy storage at power plants may provide "black-start" capability (power for plants that need electricity to start up).

Energy storage may have special use in applications such as momentary carry-over for short outages to high-value industrial processes and/or plants, voltage support, power factor correction and other aspects of power quality.

Energy storage facilitates the interconnection among different generation plants from renewable (solar, wind, fuell-cells, ...) and may make them more reliable and efficient.

In a power system where distribution grids provide an energy storage, base-load generation units (typically, coal or nuclear power plants) could properly and efficiently operate at the full power for all time, with the surplus of generated energy being available for charging the energy storage system.

Taking advantage of the new contest of the free market of the electrical energy, in a distribution grid with energy storage systems, electrical energy can be purchased during a low load demand, at low rates, can be stored and, then, can be sold, during a peak of the load demand, at a higher rate.

The American Electric Power Company (AEP) ranks among the nation's largest generators of electricity, owning nearly 38.000 megawatts of generating capacity in the U.S. In the recent years, AEP studied the direct and indirect benefits, strengths and weaknesses of distributed energy storage systems (DESS) and chose to transform its entire utility grid into a system that achieves optimal integration of both central and distributed energy assets. To that end, AEP installed the first NAS battery-based energy storage system in North America. After one year of operation and testing, AEP has concluded that, although the initial costs of DESS are greater than conventional power solutions, the net benefits justify the AEP decision to create a grid of DESS with intelligent monitoring, communications, and control, in order to enable the utility grid of the future [Nourai \& Kearns, 2010]. 


\section{Losses and power generation improvements in grid-connected PV plants}

\subsection{Losses}

In this section the most common losses on grid-connected PV plants will be briefly recalled, in order to better understand current and future solutions that can be used to mitigate this important problem.

\subsubsection{Losses caused by the mismatching between the PV plant and the grid}

One of the most critical problem for grid-connected PV plant is, undoubtedly, that of the mismatch, that can occur at a given time, between the power injection capability of the PV plant and the power absorption capability of the grid. By considering the grid fully passive and resistive, for the sake of simplicity, this problem can be appreciated with the help of Fig.1.(a), in which the working point of the system composed by the PV plant and the grid is graphically found by superimposing the I-V characteristic of the PV plant with the I-V characteristic of the grid. In practice, at a given time, the said working point can be significantly different from that in which the power exchanged between the PV plant and the grid is equal to the maximum power that the PV plant could generate (MPP). Furthermore, the working point changes if the equivalent resistance of the grid changes and/or if the solar irradiation (SI) of the PV field changes. Obviously, this phenomenon - if not controlled - may cause significant generating power losses.

\subsubsection{Losses caused by mismatching conditions among PV modules of the PV plant} Important mismatching in working conditions of different PV modules of the same PV plant can occur, essentially because of:

- discrepancies in module parameter values caused by manufacturing tolerances,

- different module ageing effects,

- different orientations of modules.

Furthermore, especially in a urban residence, where PV modules of a PV plant are normally installed on the roofs, in addition to shadows created by clouds, those created by neighbouring buildings, trees, power and/or telephone lines, sometimes, partially cover PV modules (partial shadowing), so creating a condition of mismatching or "unbalanced generation" among different PV modules.

It is, also, well known that, in order to allow the utility-interactive power electronic inverter to obtain sufficient DC voltage, a lot of PV modules are usually connected in series, so making up a so called "PV string".

In case of mismatching conditions, the current generated by a PV string is physically imposed to be equal to the minimum current value, corresponding to the current generated by the most unfavourably irradiated PV module of the PV string, and, finally, the whole power generated by the PV string can be unfavourably reduced with respect to the maximum available power. In other words, a significant reduction in the total output power of the PV system is often observed under the aforementioned mismatching conditions. In order to alleviate the aforementioned problem, traditionally, a bypass diode is connected in parallel with each PV module; this alleviates the power reduction of the PV string, however, the shaded PV modules cannot generate their inherent power, and hence the problem has no its optimal solution. 


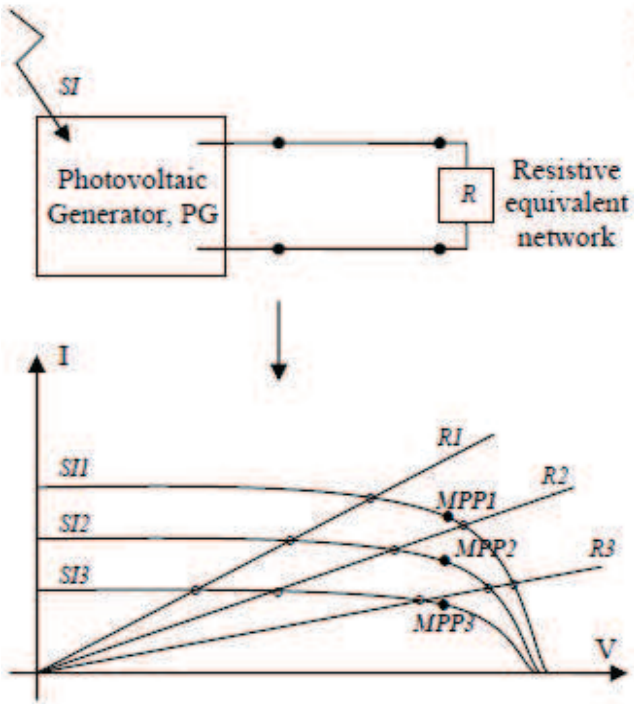

(a) Simplified scheme and I-V characteristics of a conventional grid-connected PG
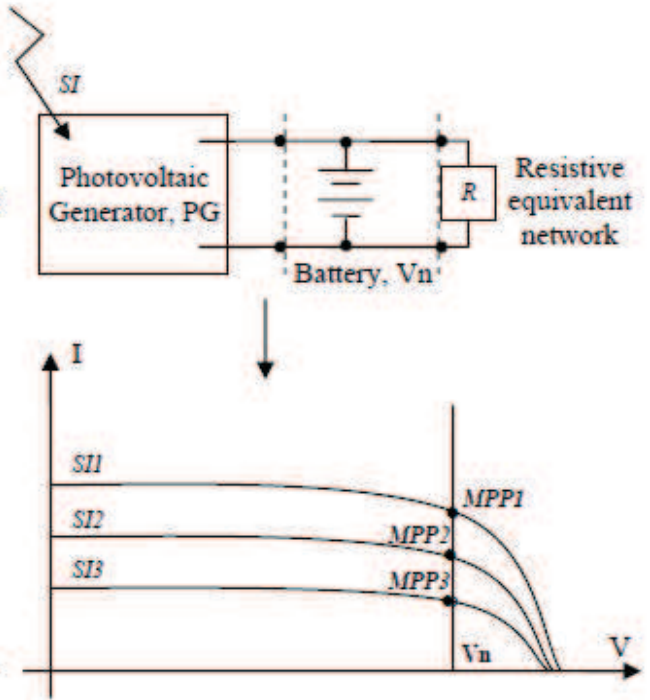

(b) Simplified scheme and I-V characteristics of grid-connected PG in presence of batteries

Fig. 1. Working points analysis of grid-connected photovoltaic systems, without (a) and with (b) the use of batteries.

\subsubsection{Losses caused by the reversed power flow on grids}

Radial power distribution grids are designed for a power flow from the high voltage (HV) side to the low voltage (LV) side.

In presence of Grid-connected PV plants, power flow is reversed from the end of LV side to the HV side of grids and his may cause voltage rise of LV line. To prevent the over voltage of the power distribution lines, power electronic inverters for PV plants (i.e. for Japanese PV plants [Ueda et al., 2006]) have a function that regulate the output power when the voltage of the grid is too high; because of this function, significant amount of electric power of PV plants can be lost [Ueda et al., 2006].

\subsection{MPPT techniques}

After discussing about power losses on grid-connected PV plants, some of the most diffused techniques, utilized for mitigating them, are now recalled.

In general terms, techniques for optimising power generated by PV plants are known as maximum power point tracking (MPPT) techniques.

\subsubsection{Active MPPTs}

As well known, losses evidenced in section 3.1.1 are usually and effectively avoided by implementing on power electronic interfacing apparatus (inverters) control logics able to optimize power flows between the PV plant and the grid; they are based on algorithms precisely conceived for maximizing the power injected into the grid by the PV plant and they are known as "active MPPTs". 
In principle, these algorithms can be directly implemented on single-stage (DC-AC) PWM inverters; however, usually they are more profitably implemented on double-stage (DC-DC and DC-AC) PWM inverters, in which the DC-DC power electronic converter (widely, a boost type converter) is specifically devoted to the implementation of the selected MPPT algorithm.

There a lot of different MPPT algorithms, characterized by different performances, that are available for being implemented on PWM inverters; because this subject has been widely discussed and consolidated in the specialized literature [Esram and Chapman, 2007], here, these algorithms are not explicitly discussed.

\subsubsection{Distributed active MPPTs}

In case of mismatching conditions recalled in section 3.1.2, the use of a by-pass diode in parallel to each PV module of a PV string can mitigate losses of generating power but does not optimally solve the problem of maximizing the power generated by the PV string, neither by using, as interfacing apparatus, a PWM inverter endowed with a MPPT function. In fact, for instance, please consider the presence of mismatched conditions in the case of a PV string constituted by two series-connected PV modules (each of one with a by-pass diode in parallel); the corresponding generation current-voltage characteristic curves of each PV module are depicted in Fig.2(a) [Shimizu et Al., 2003].

Furthermore, the characteristic curves of the output-current and of the output-power versus the output-voltage are as in Fig.2(b), that can be justified by means of the following considerations.

By varying the value of the equivalent resistance of the grid as seen by the PV string, the PV string current, Io, can goes from Ia to Id; the PV string voltage, Vo, and the PV string generated power, Po, change as follows:

- $\quad$ when Io = Ia (operating point A), both PV modules generate power, but neither one generates maximum power;

- $\quad$ when Io = Ib (operating point B), the shaded PV module generates maximum power, but the non-shaded PV module does not generate maximum power;

- $\quad$ when Io = Ic (operating point C), the non-shaded PV module generates power, but the shaded PV module does not generate any power, because the PV string current, Io, flows through its bypass diode;

- $\quad$ when Io = Id (operating point D), the non-shaded PV module generates its maximum power, but the shaded PV module does not generate any power because the PV string current, Io, flows through its bypass diode.

Finally, the output-power versus the output-voltage characteristic of the PV string is a multi-modal curve having a number of peaks (maximum) equal to the number of the string PV modules.

This means that, also with the use of the module by-pass diodes, in case of mismatching conditions the maximum output power of the PV string is less than the sum of the maximum generation power of the PV modules. In fact, with reference to the aforementioned situation, it is simple to underline that if the shaded PV module is not shortcircuited, the non-shaded PV module does not operate at its maximum power; if the shaded PV module is short-circuited it does not generate its inherent power.

That said, it also evident that the presence of more than one maximum in the P-V characteristic of a PV string makes very difficult, for conventional active MPPTs, the detection of the absolute maximum power point of the PV string, to be caught. 


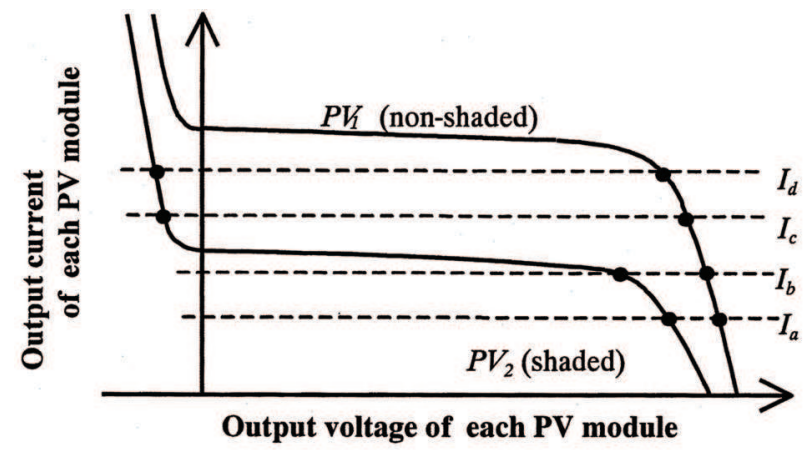

(a)

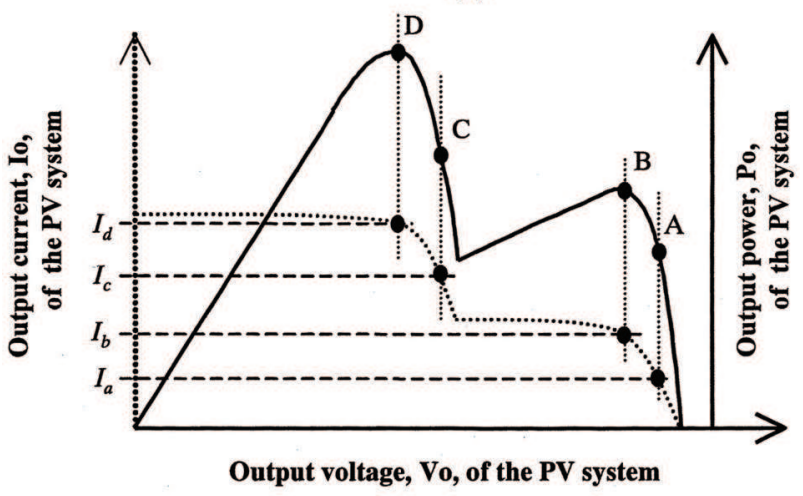

(b)

Fig. 2. PV module output current versus PV module output voltage, for different irradiation levels, 2(a), and effects of different solar irradiation levels on a string composed by two PV modules connected in series, 2(b). [Shimizu et Al., 2003]

Once analysed the presence of mismatching conditions in PV strings and their negative effects on their power generation, it is of practical relevance to investigate the possibility of finding a technical and cost-effective solution to such a problem, also taking into account of different layouts that are available for grid-connected PV plants and that have been discussed in a relevant number of recent papers and technical reports.

Intuitively, PV plant layouts with more inverters (string and/or module inverters) should be less sensitive to mismatching conditions with respect to PV plant with one centralized inverter only. However, in some recent studies [Woytea et al., 2003] it was also shown that this last assumption can not be always true and, in certain plant configurations, a plant layout with more inverters can result in partial shadowing related losses greater than that of a centralized inverter plant layout. This last situation is essentially related to the presence of multi-modal PV string or PV module power-voltage characteristics which create serious problems to conventional inverter active MPPT techniques. In fact, in presence of more than one local maximum points in the power-voltage characteristic of a PV string and/or a PV 
module, conventional inverters implementing active MPPT techniques can catch and maintain one of the local maximum power points instead of the absolute maximum power point, so causing significant reductions in the PV plant whole generated power.

To overcome the aforementioned problems, essentially related to characteristics of conventional inverter active MPPT techniques and algorithms, in the recent specialized literature, different novel active MPPT techniques have been introduced and discussed, with the specific aim of maximizing the power generated by a PV string in case of significant mismatching conditions.

These new active techniques are essentially based on the idea that the MPPT function can be extended to each PV module of a string by implementing a so called distributed active MPPT (DMPPT) function.

Different techniques and algorithms have been, also, proposed in order to implement the aforementioned DMPPT. However, they are generally based on the use of expensive and complex high-frequency switching circuits and control techniques.

In [Shimizu et Al., 2003], a practical implementation of the aforementioned DMPPT technique is achieved by introducing a proper generation control circuit (GCC), that is to say a number of multi-stage DC/DC converter circuits to be connected in cascade to each module of a PV string, together with a centralized utility interactive inverter. In this way, the generation point of each PV module can be independently controlled and maximized. Furthermore, the P-V characteristic of a PV string results in a mono-modal characteristic with only a maximum power point to be caught by the MPPT algorithm, also in the presence of PV module mismatching conditions. A specific advantage of this technical solution is that power generation of each module can be maximized by physically detecting and controlling only the output power of the PV plants, so avoiding additional expensive power detectors to be installed on PV modules, on the contrary needed in other similar DMPPT techniques.

However, the proposed configuration circuit remains complex with respect to other circuit configurations with no distributed active DC/DC PV module converters.

\section{Batteries as passive MPPTs}

In this section it will be shown as batteries, connected in parallel to of PV field, can operate the aforementioned MMPT function passively, that is to say without the use of any additional circuitry and without implementing any control logic.

However, expected performances of this kind of passive MMPT technique are worse if compared with that of the aforementioned active techniques, mainly because of variation of the MPP caused by variations of working temperature of PV modules.

For these, reasons, after introducing the use of batteries in a centralized manner, this passive technique is extended to a different scenario in which batteries are contemplated to be more profitably used in a distributed manner.

\subsection{The use of batteries in a centralized manner}

For a fixed level of the solar irradiation and for a fixed temperature, the power delivered to the network by a conventional grid-connected PG, which qualitative I-V characteristic has been shown in Fig.1.(a), depends on the value of the network equivalent impedance as seen from the PG terminals, the behaviour of the network being normally imposed to be resistive by using a power electronic PWM inverters. 
Unfortunately, only one working point on the I-V PG characteristic corresponds to the MPP (bold-faced circles, in Fig.1.(a) and it can be "caught" only carefully adjusting the value of the network equivalent resistance (i.e. by using the aforementioned active MPPT apparatus). On the other hand, Fig.1 also shows that, for different solar irradiation (SI) levels, the variation of the MPP directly involves the PG current values, while the PG voltage values remain almost constant.

This means that a battery, in parallel with the PG and the network as shown in Fig.1.(b), if properly designed in its nominal voltage value and in its capacity, can naturally catch and maintain a PG working point very close to the MPP, for any PG solar irradiation level and for any value of the network equivalent resistance (Fig.1.(b)).

Nevertheless, it is expected that battery used as passive MPPT has lower performances if compared with currently utilized active MPPTs, mainly because of the variations of the PG voltage at the MPP caused by variations of PG working temperature.

Because of this last consideration, as an alternative to the trivial idea of utilizing batteries in grid-connected PV systems in a centralized way and in the place of active MPPTs, it is proposed to use batteries in large grid-connected PV plants and in a more effective "distributed way", that is discussed in the next section.

\subsection{The use of batteries in a distributed manner}

The proposed idea of utilising batteries in large grid-connected PV plants and in a profitable "distributed way" can be explained and appreciated with the help of Fig.3.

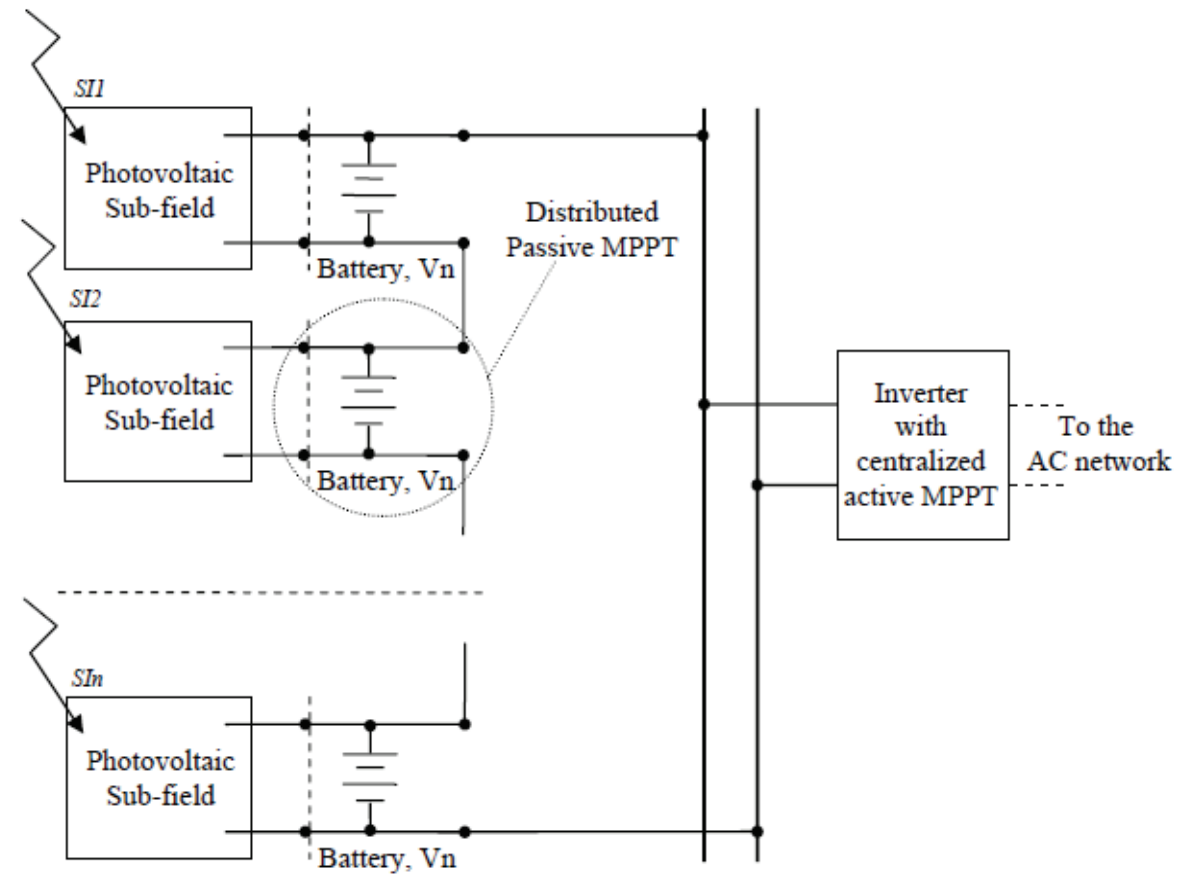

Fig. 3. Grid-connected photovoltaic system with distributed use of batteries as distributed passive MPPTs and centralized inverter with active MMPT function. 
In practice, in large grid-connected PV plants, batteries can be used as passive and distributed MPPTs by locating them in parallel with a proper number of PV sub-fields and by maintaining a centralized inverters with centralized active MPPT function.

At the designing stage of the battery distributed system, there are some questions that have to be well analysed, in order to obtain an effective and inexpensive system. Firstly, the grouping of the PV modules, with which to build the PV sub-field. Then, the choice of the nominal voltage of the battery sub-systems to be connected in parallel to each PV sub-field. Finally, the choice of the capacity of the whole battery storage system.

The grouping of the PV modules is strictly connected to the choice of the nominal voltage of the battery sub-systems; it is worthwhile to remember that the nominal voltage of the battery sub-system has to be very close to the MPP voltage of the related PV sub-field and this last is approximately equal to $75-80 \%$ of the PV sub-field open circuit voltage.

In choosing the capacity of the battery system, the criterion to be followed is that of making a passive MPPT system that has to be effective but also inexpensive, in order to result as a valid alternative to the aforementioned, more complex and expensive, PV plant electrical schemes endowed by a number of distributed power electronic DC-DC converters. Furthermore, it is important to take into account also that: (i) energy generated by PV subfields - normally - has to be stored only for very short times (just to cope for the momentary unavailability of the grid); (ii) the active MPPT function of the centralized inverter should be able to avoid the full charge of batteries, even if they have a small capacity.

\section{Experimental tests}

In order to test the effectiveness of the proposed passive MPPT technique for grid-connected photovoltaic plants, that is based on the temporary storage of the generated power on a proper designed distributed battery system, two different experimental measurement campaigns have been performed; the first refers to laboratory experimental tests on a smallscale photovoltaic generator prototype of $20 \mathrm{Wp}$ (section 5.1) while the second refers to experimental tests on a fully realized and installed grid-connected photovoltaic plant of 3 $\mathrm{kWp}$ (section 5.2).

\subsection{Experiments on a small-power 20 Wp PV prototype}

A small-scale prototype of about $20 \mathrm{Wp}$ of power, constituted by 4 identical PV smallmodules of about $5 \mathrm{Wp}$, together with 8 ( 2 for each panel) NiCd rechargeable batteries with $1.2 \mathrm{~V}$ of nominal voltage and $800 \mathrm{mAh}$ of capacity, has been built-up and experimented under different artificial irradiation conditions (obtained by utilizing 4 flood light apparatus with $4 \times 250 \mathrm{~W}$ lamps).

In practice, by following the guidelines of the electrical scheme depicted in Fig.3, in which the PV sub-fields are foreseen to be series connected, the prototype has been tested under both balanced and unbalanced artificial irradiation conditions.

In this experimental case study, the inverter is not present and, taking into account that in practice inverters for grid-connected PV plants have to inject into the grid a sinusoidal current in phase with the grid voltage, it has been substituted with a simple equivalent resistor, Ro; different values (optimal and non-optimal) for the inverter-grid equivalent resistance have been also considered in order to verify the effects of a conventional (centralized) MPPT function, typically performed by aforementioned inverters. 
Even if a several number of experiments have been performed and analysed, for the sake of brevity, in the next, only the most interesting experimental results are referred and briefly discussed.

Specifically, in Tables I and II, the values of the power generated by each PV small-module and by the whole PV generator (4 series-connected small-modules), under balanced artificial irradiation levels and for optimal (Table I) and non optimal (Table II) values of the invertergrid equivalent resistance, are summarized.

Experimental results confirm that, for a fixed and balanced (solar) irradiation (SI) level, a whole PV Plant can generate its inherent maximum power only if the inverter (thanks to its active MPPT function) is able to impose to the grid a resistive behaviour with a specific resistance value (optimal value).

In Tables III, the values of the power generated by each PV small-module and by the whole PV generator, under unbalanced artificial irradiation levels and for the optimal value of the inverter-grid equivalent resistance, are summarized.

\begin{tabular}{|c|c|c|}
\hline \multicolumn{3}{|c|}{ Generated Power [W] } \\
\hline $\begin{array}{c}\text { Without } \\
\text { batteries }\end{array}$ & $\begin{array}{c}\text { With } \\
\text { batteries }\end{array}$ \\
\hline $\begin{array}{c}\text { PV Panel 1 } \\
\left(\mathrm{SI} 1=177 \mathrm{~W} / \mathrm{m}^{2}\right)\end{array}$ & 0.63 & 0.61 \\
\hline $\begin{array}{c}\text { PV Panel 2 } \\
\left(\mathrm{SI} 2=180 \mathrm{~W} / \mathrm{m}^{2}\right)\end{array}$ & 0.64 & 0.62 \\
\hline $\begin{array}{c}\text { PV Panel 3 } \\
\left(\mathrm{SI} 3=175 \mathrm{~W} / \mathrm{m}^{2}\right)\end{array}$ & 0.63 & 0.60 \\
\hline $\begin{array}{c}\text { PV Panel 4 } \\
\left(\mathrm{SI} 4=170 \mathrm{~W} / \mathrm{m}^{2}\right)\end{array}$ & 0.61 & 0.59 \\
\hline Whole PV Plant & 2.51 & 2.42 \\
\hline
\end{tabular}

Table I. Results under balanced SI of PV Panels and optimal value of the inverter-grid equivalent resistance, Ro.

\begin{tabular}{|c|c|c|}
\hline \multicolumn{3}{|c|}{ Generated Power [W] } \\
\hline $\begin{array}{c}\text { Without } \\
\text { batteries }\end{array}$ & $\begin{array}{c}\text { With } \\
\text { batteries }\end{array}$ \\
\hline $\begin{array}{c}\text { PV Panel 1 } \\
\left(\mathrm{SI}=177 \mathrm{~W} / \mathrm{m}^{2}\right)\end{array}$ & 0.53 & 0.60 \\
\hline $\begin{array}{c}\text { PV Panel 2 } \\
\left(\mathrm{SI} 2=180 \mathrm{~W} / \mathrm{m}^{2}\right)\end{array}$ & 0.54 & 0.61 \\
\hline $\begin{array}{c}\text { PV Panel 3 } \\
\left(\mathrm{SI} 3=175 \mathrm{~W} / \mathrm{m}^{2}\right)\end{array}$ & 0.52 & 0.60 \\
\hline $\begin{array}{c}\text { PV Panel 4 } \\
\left(\mathrm{SI} 4=170 \mathrm{~W} / \mathrm{m}^{2}\right)\end{array}$ & 0.50 & 0.58 \\
\hline Whole PV Plant & 2.09 & 2.39 \\
\hline
\end{tabular}

Table II. Results under balanced SI of PV Panels and non optimal value of the inverter-grid equivalent resistance (-25\% of Ro) 


\begin{tabular}{|c|c|c|}
\hline \multicolumn{3}{|c|}{ Generated Power [W] } \\
\hline & $\begin{array}{c}\text { Without } \\
\text { batteries }\end{array}$ & $\begin{array}{c}\text { With } \\
\text { batteries }\end{array}$ \\
\hline $\begin{array}{c}\text { PV Panel 1 } \\
\left(\mathrm{SI} 1=224 \mathrm{~W} / \mathrm{m}^{2}\right)\end{array}$ & 0.50 & 1.05 \\
\hline $\begin{array}{c}\text { PV Panel 2 } \\
\left(\mathrm{SI} 2=220 \mathrm{~W} / \mathrm{m}^{2}\right)\end{array}$ & 0.51 & 0.98 \\
\hline $\begin{array}{c}\text { PV Panel 3 } \\
\left(\mathrm{SI} 3=66 \mathrm{~W} / \mathrm{m}^{2}\right)\end{array}$ & 0.11 & 0.23 \\
\hline $\begin{array}{c}\text { PV Panel 4 } \\
\left(\mathrm{SI} 4=280 \mathrm{~W} / \mathrm{m}^{2}\right)\end{array}$ & 0.53 & 1.18 \\
\hline Whole PV Plant & 1.65 & $\mathbf{3 . 4 4}$ \\
\hline
\end{tabular}

Table III. Results under unbalanced SI of PV Panels and optimal value of the grid equivalent resistance, Ro

Experimental results show that, when the series connected PV sub-fields of a PV plant are irradiated in a non uniform way (unbalanced irradiation), even if in presence of a centralized inverter endowed with an active MPPT function, a conventional PV plants (without batteries) does not appear able to extract from the whole PV plant its inherent maximum power, that is to say the sum of the inherent maximum power of each PV subfield; this is because the whole PV plant current, in a series connected PV sub-field system, is imposed to be equal to the lowest value among that of the different PV sub-fields.

Experimental results also show that, by introducing a properly designed distributed battery system, also in case of unbalanced solar irradiation conditions, it seems possible to significantly improve the power generated by the whole PV plant.

\subsection{Experiments on a $3 \mathrm{kWp}$ grid-connected PV plant}

The analysis is specifically referred to a physically realized $18 \mathrm{kWp}$ PV plant, connected to the LV distribution grid and owned by the B\&T Solar Energy Division Company, on Lazzaro (RC), Italy. With some more details, the PV plant is realized by means of $90 \mathrm{PV}$ modules with $200 \mathrm{Wp}$ and with an open circuit voltage of about $40 \mathrm{~V}$; PV modules are grouped in $3 \mathrm{PV}$ sub-fields (with 30 modules and $6 \mathrm{kWp}$ ) connected to the grid by means of three different single-phase PWM inverters. Because of each inverter has two separate DCinputs, with separate DC-DC boost-converter operating the MPPT function, each sub-field is realized with 2 different groups of 15 series-connected PV modules.

For our experimental tests and measurements, only one group of 15 series-connected PV modules $(3 \mathrm{kWp})$ of a single-phase PV sub-field has been considered; furthermore, because of the temporarily limited availability of batteries, only 9 modules of the 15 series-connected PV modules have been experimented with (and without) batteries.

Specifically, 6 PV modules are always operated without batteries and are series-connected. On the other hand, the remaining 9 PV modules are grouped in 3 groups of 3 PV modules connected in parallel. Finally, the 3 parallel-connected PV modules are connected in series among them and also with the remaining 6 series-connected PV modules.

In order to test the effectiveness of the battery energy storage capability, a group of three $12 \mathrm{~V}, 10 \mathrm{Ah}$, lead-acid series-connected batteries are connected (via a bipolar circuit breaker) in parallel to each aforementioned group of 3 parallel-connected PV modules. 
Fig.4 should be helpful to graphically summarize the circuit configuration of the experimented PV plant.

Experimental tests have been operated under both balanced and unbalanced solar irradiation conditions of PV modules; in both cases, the results of measurements have been utilized to perform a comparative analysis between the power generated by the PV modules (and, then, by the whole PV sub-field), under the same irradiation conditions, without and with the use of batteries.

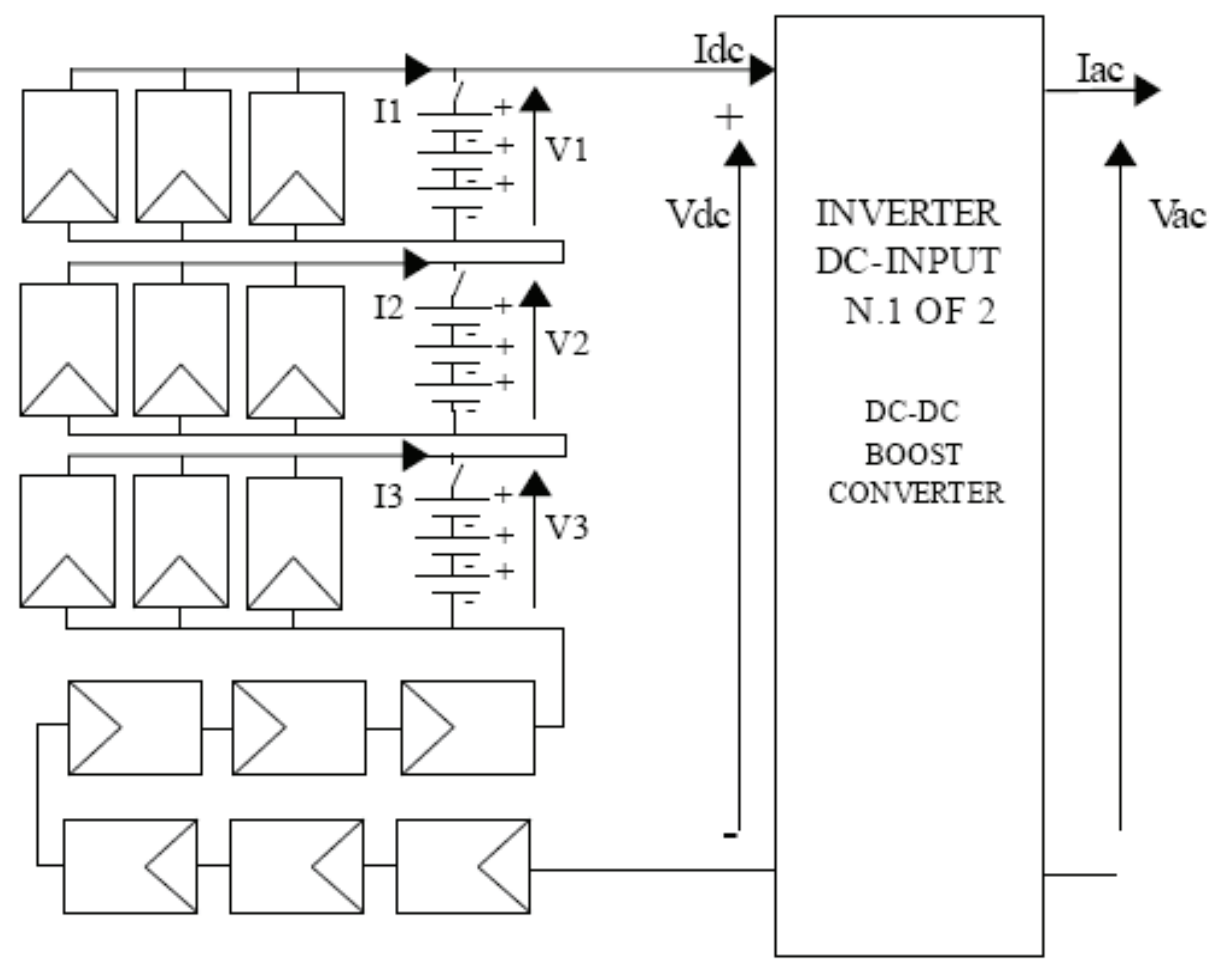

Fig. 4. Electrical scheme of the experimentally tested $3 \mathrm{kWp}$ grid-connected PV plant

The first experimental test refers to balanced solar irradiation conditions. It is worthwhile to underline that, the weather being cloudy, the irradiation level was low (no more than 300 $\mathrm{W} / \mathrm{m}^{2}$ ). Measurements have been carried out for a total duration of one hour; during the first 30 minutes, batteries are switched-off while, during the second 30 minutes, batteries are switched-on. The results of measurements are summarised in Table IV in terms of registered time mean values. It is evident that, when connecting batteries, power generated by each group of PV modules, under the same solar irradiation conditions, increases. However, being the whole power of the PV plant injected into the grid, practically, the same than that injected without the presence of batteries, in this case the surplus of generated power is temporarily stored into the batteries and it will be injected into the grid later.

The second experimental test refers to unbalanced solar irradiation conditions; in practice, two PV modules have been artificially shadowed, as graphically evidenced in Fig.5. 


\begin{tabular}{|c|c|c|c|c|c|c|c|c|c|}
\hline \multicolumn{10}{|c|}{$\begin{array}{l}\text { Measured quantities (time mean values) } \\
\text { - symbols are as in Fig.4 - }\end{array}$} \\
\hline $\begin{array}{c}\text { I1 } \\
{[\mathrm{A}]}\end{array}$ & $\begin{array}{l}\text { V1 } \\
{[\mathrm{V}]}\end{array}$ & $\begin{array}{c}\text { I2 } \\
{[\mathrm{A}]}\end{array}$ & $\begin{array}{l}\mathrm{V} 2 \\
{[\mathrm{~V}]}\end{array}$ & $\begin{array}{c}\text { I3 } \\
\text { [A] }\end{array}$ & $\begin{array}{c}\text { V3 } \\
\text { [V] }\end{array}$ & $\begin{array}{l}\text { Idc } \\
\text { [A] }\end{array}$ & $\begin{array}{l}\text { Vdc } \\
{[\mathrm{V}]}\end{array}$ & $\begin{array}{l}\text { Iac } \\
{[A]}\end{array}$ & $\begin{array}{l}\text { Vac } \\
{[V]}\end{array}$ \\
\hline \multicolumn{10}{|c|}{ Without batteries } \\
\hline 2,7 & 37,8 & 2,7 & 38,0 & 2,7 & 38,1 & 2,7 & 356,0 & 4,1 & 225,0 \\
\hline \multicolumn{10}{|c|}{ With batteries } \\
\hline 3,1 & 37,2 & 3,2 & 37,7 & 3,2 & 37,5 & 2,7 & 356,0 & 4,2 & 224,0 \\
\hline
\end{tabular}

Table IV. Results of measurements under balanced solar irradiation conditions

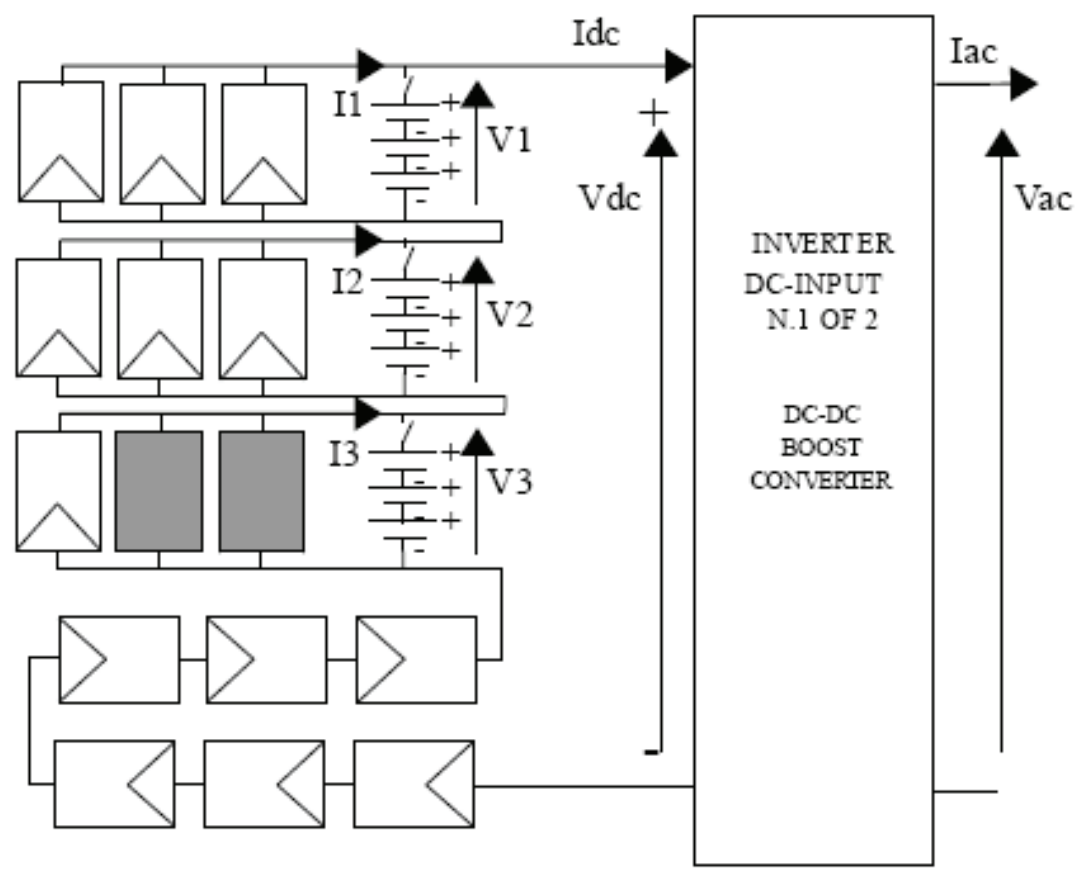

Fig. 5. Electrical scheme of the experimentally tested $3 \mathrm{kWp}$ grid-connected PV plant, in presence of an artificially imposed partial shadowing of PV modules

Measurements have been carried out for a total duration of one hour:

- during the first interval of 15 minutes, batteries are switched-off and all the PV modules are irradiated,

- during the second interval of 15 minutes, batteries are switched-off and two PV modules are artificially shadowed;

- during the third interval of 15 minutes, batteries are switched-on and all the PV modules are irradiated,

- during the fourth interval of 15 minutes, batteries are switched-on and two PV modules are artificially shadowed.

The results are summarised in Table $\mathrm{V}$ in terms of registered time mean values. 
Measured quantities (time mean values)

- symbols are as in Fig.5 -

\begin{tabular}{|c|c|c|c|c|c|c|c|c|c|}
\hline $\begin{array}{c}\text { I1 } \\
\text { [A] }\end{array}$ & $\begin{array}{c}\text { V1 } \\
{[\mathrm{V}]}\end{array}$ & $\begin{array}{c}\text { I2 } \\
{[\mathrm{A}]}\end{array}$ & $\begin{array}{c}\text { V2 } \\
{[\mathrm{V}]}\end{array}$ & $\begin{array}{c}\text { I3 } \\
{[\mathrm{A}]}\end{array}$ & $\begin{array}{c}\text { V3 } \\
{[\mathrm{V}]}\end{array}$ & $\begin{array}{c}\text { Idc } \\
{[\mathrm{A}]}\end{array}$ & $\begin{array}{c}\text { Vdc } \\
{[\mathrm{V}]}\end{array}$ & $\begin{array}{c}\text { Iac } \\
{[\mathrm{A}]}\end{array}$ & $\begin{array}{c}\text { Vac } \\
{[\mathrm{V}]}\end{array}$ \\
\hline \multicolumn{8}{|c|}{ Without batteries and all PV-modules irradiated } \\
\hline 2,1 & 38,8 & 2,1 & 38,4 & 2,1 & 38,7 & 2,1 & 352,0 & 3,2 & 227,0 \\
\hline \multicolumn{8}{|c|}{ Without batteries and two PV-modules shadowed } \\
\hline 1,2 & 36,8 & 1,2 & 37,9 & 1,2 & 38,1 & 1,2 & 349,0 & 1,8 & 224,0 \\
\hline \multicolumn{8}{|c|}{ With batteries and all PV-modules irradiated } \\
\hline 1,9 & 37,2 & 2,2 & 37,7 & 2,0 & 37,7 & 2,3 & 347,0 & 3,6 & 223,0 \\
\hline \multicolumn{8}{|c|}{ With batteries and two PV-modules shadowed } \\
\hline 1,6 & 37 & 1,8 & 36,7 & 1,6 & 36,9 & 1,9 & 353,0 & 2,9 & 226,0 \\
\hline
\end{tabular}

Table V. Results of measurements under unbalanced solar irradiation conditions

In order to better summarize the experimental results and to better appreciate what happens, especially in case of unbalanced solar irradiation conditions, with and without the use of batteries, let us to define a Power Decay Coefficient, PDC\%, that is to say a coefficient that measures the decay rate of the power generated by all the PV modules as a consequence of the shadowing of only some PV modules of the whole PV field:

$$
\text { PDC } \%=\frac{\text { (Power without shadows - Power with shadows })}{\text { Power without shadows }} \times 100
$$

Then, with reference to Table $\mathrm{V}$, the value of PDC\%, without and with batteries, are reported in Fig.6.

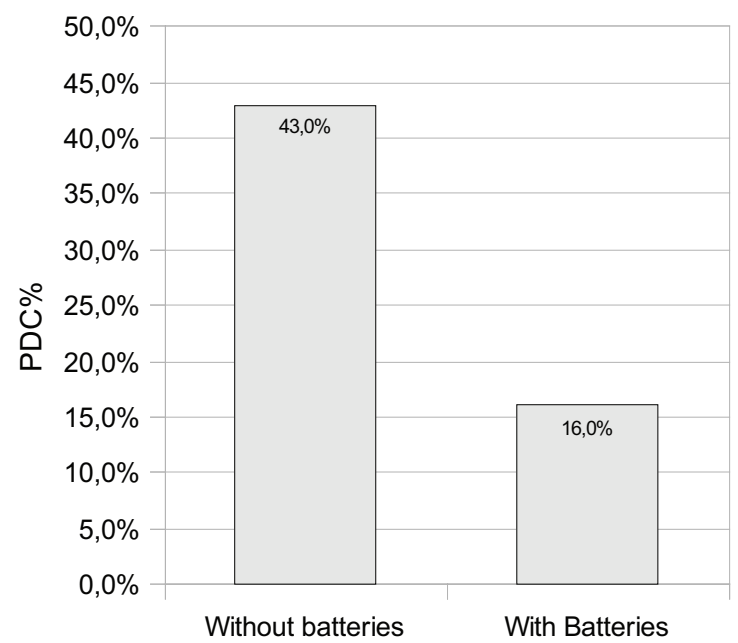

Fig. 6. Decay rate (PDC\%) of the PV plant generated power, in presence of partial shadowing of PV modules, without ant with the use of batteries, as suggested in Fig.3. 
It is possible to note that, partial shadowing of only a limited number of PV modules, in conventional (without batteries) PV plants, can cause an important decay of the whole generated power $(43 \%)$; on the contrary, in presence of batteries, the same partial shadowing causes a decay rate of the whole generated power significantly lower (only 16\%).

\section{Perspectives on developing single AC PV modules, with on board distributed batteries used for energy storage}

From results and considerations of previous sections, it can be summarized that the intrinsic variability of solar irradiation forces conventional grid-connected PV plants to inject power into the grid in a way as variable and unpredictable.

Furthermore, as well known, conventional PWM inverters, for connecting PV plants to distribution grids, generate an AC output voltage characterized by harmonic and interharmonic components (especially at high frequencies, in the range of their switching function). Even if output filters are conventionally used, remaining harmonics and interharmonics may cause different power quality problems, especially in terms of malfunctioning of information and communication technology (ICT ) apparatus, that are more and more utilized in modern distribution grids.

Currently, in the specialized scientific literature, researchers are brightly discussing about the possibilities to develop new power electronic apparatus for interconnecting PV plants and the distribution grids with power quality problems reduced with respect to that caused by conventional PWM inverters [Busquets-Monge et al., 2008].

On this basis, on the opinion of the Author, the idea here investigated to introduce in gridconnected PV plants an energy storage system, based on a conspicuous number of batteries with small capacity and operated in a distributed manner, can be utilized also for defining and developing new multi-level power electronic inverters [Khomfoi \& Tolbert, 2007] intrinsically characterized by AC output voltages with very high quality waveforms and, also, by high reliability and availability.

Particularly interesting could be the idea of developing single PV modules able to generate an AC output voltage (AC PV modules) directly compatible with the low voltage distribution grids and with high quality waveform, being this achievable by means of a proper designed and developed multi-level inverter installed on the PV modules.

With some more details, by installing on a conventional PV module a conspicuous number of small rechargeable batteries, to be put in parallel to a proper group of series connected PV cells, an as many conspicuous number of DC voltage levels is physically available on board of the PV module and these DC voltage levels can be utilized, by a proper designed and developed multi-level electronic inverter, to build up an AC quasi-sinusoidal voltage at the distribution grid frequency; an isolation transformer (a HF-transformer on the DC section of the circuit or a LF-transformer on the AC output section of the circuit) could be also utilized to adjust the AC output voltage rms value of the PV module and to cope for galvanic isolation. In addition to the high quality waveform of the AC output voltage, batteries installed on the PV module would make it more efficient, available and reliable.

\section{Conclusion}

A passive MPPT technique, to be utilized mostly in large grid-connected PV plants, has been introduced and discussed; it is essentially based on the energy storage capabilities of 
batteries that are proposed to be put in parallel to a proper number of PV sub-fields, so as to be used in a distributed manner. If well designed in their location, in their nominal voltage value and in their capacity, batteries can naturally catch the MPP of each PV sub-field, also compensating for critical unbalanced solar irradiation conditions.

The results of different experimental tests, operated both on a very small-power $20 \mathrm{Wp}$ prototype and on a $3 \mathrm{kWp}$ physically realized grid-connected PV plant, have clearly demonstrated the effectiveness of the proposed technique, also showing that, in some critical irradiation conditions, batteries used in grid-connected PV plants can significantly increase the energy generation with respect to that of a conventional PV plant. The proposal can be a valid and lower cost alternative to more expensive solutions based on a number of DC-DC power electronic converters to be put in parallel to each PV sub-field in order to work as distributed active MPPTs.

Furthermore, the presence of an energy storage system can make more and more attractive grid-connected PV plants, due to some important additional capabilities not commons of currently conceived grid-connected PV plants, as: a more great availability in favour of the AC power grid; a significant reduction of unfavourable requests of occasional peaks of load power demand; the possibility to substitute other expensive (and often not renouncing) apparatus for utility grid power quality improvements, as UPS and active filters; the possibility to be integrable with other different renewable resources, with minor expenses and with great economical advantages.

Finally, a conspicuous number of batteries distributed on board to a single PV module could be on the basis of the development of AC PV modules, to be directly connected to LV distribution grids and characterized by high quality of AC voltage, high efficiency and high availability.

\section{References}

Busquets-Monge, S.; Rocabert, J.; Rodriguez, P.; Alepuz, S.; Bordonau, J. (2008). Multilevel Diode clamped Converter for Photovoltaic Generators with Independent Voltage Control of Each Solar Array. IEEE Transactions on Industrial Electronics, Vol.55, July 2008, pp. 2713-2723.

Carbone, R. (2009). Grid-Connected Photovoltaic Systems with Energy Storage. Proceeding of IEEE International Conference on CLEAN ELECTRICAL POWER, Renewable, Energy Resources Impact "ICCEP 2009". Capri - Italy, June 9-11, 2009.

Denholm, Paul; Margolis, Robert M. (2007). Evaluating the limits of solar photovoltaics (PV) in electric power systems utilizing energy storage and other enabling technologies. ELSEVIER, Energy Policy 35, (2007) 4424-4433. www.elsevier.com/locate/enpol.

Esram, T.; Chapman, P.L. (2007). Comparison of Photovoltaic Array Maximum Power Point Tracking Techniques. IEEE Transactions on Energy Conversion, Vol.22, N.2, June, 2007, pp.439-449.

Khomfoi, S.; Tolbert, L.M. (2007). Multilevel Power Converters. Power Electronics Handbook, 2nd Edition, Elsevier, 2007, ISBN 978-0-12-088479-7, Chapter 17, pp. 451-482.

Lo, Y. K.; Lin, J. Y.; Wu, T. Y. (2005). Grid-Connection Technique for a Photovoltaic System with Power Factor Correction. IEEE PEDS 2005, 0-7803-9296-5/05.

Lu, B.; Shahidehpour, M. (2005). Short-Term Scheduling of Battery in a Grid-Connected PV/Battery System. IEEE Transactions on Power Systems, Vol. 20, N², May 2005. 
Nourai, Ali; Kearns, David. (2010). Realizing Smart Grid Goals with Intelligent Energy Storage. IEEE power \& energy magazine, Vol. 49, march/april 2010. 657-R114.

Shimizu,T.; Hashimoto, O.; Kimura, G. (2003). A Novel High-Performance UtilityInteractive Photovoltaic Inverter System. IEEE Transactions on Power Electronics, Vol.18, 2003, N. 2.

Ueda, Yuzuru; Kurokawa, Kosuke; Itou, Takamitsu; Kitamura, Kiyoyuki; Akanuma, Katsumi; Yokota, Masaharu; Sugihara, Hiroyuki; Morimoto, Atsushi. (2006). Performance analyses of battery integrated grid-connected residential PV systems. Proceeding of 21st European Photovoltaic Solar Energy Conference, 4-8 September 2006, Dresden, Germany.

Woytea, Achim; Nijsa, Johan; Belmans, Ronnie. (2003). Partial shadowing of photovoltaic arrays with different system configurations: literature review and field test results. ELSEVIER Transaction on Solar Energy, Vol. 74, 2003, pp. 217-233. 


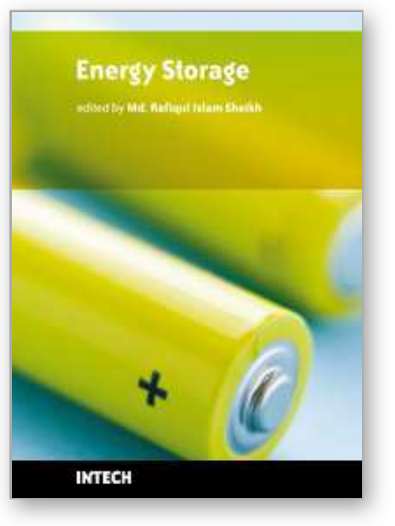

\author{
Energy Storage \\ Edited by Rafiqul Islam Sheikh
}

ISBN 978-953-307-119-0

Hard cover, 142 pages

Publisher Sciyo

Published online 27, September, 2010

Published in print edition September, 2010

Electricity is more versatile in use because it is a highly ordered form of energy that can be converted efficiently into other forms. However, the disadvantage of electricity is that it cannot be easily stored on a large scale. One of the distinctive characteristics of the electric power sector is that the amount of electricity that can be generated is relatively fixed over short periods of time, although demand for electricity fluctuates throughout the day. Almost all electrical energy used today is consumed as it is generated. This poses no hardship in conventional power plants, where the fuel consumption is varied with the load requirements. However, the photovoltaic and wind, being intermittent sources of power, cannot meet the load demand all of the time. Wherever intermittent power sources reach high levels of grid penetration, energy storage becomes one option to provide reliable energy supplies. These devices can help to make renewable energy more smooth and reliable, though the power output cannot be controlled by the grid operators. They can balance micro grids to achieve a good match between generation and load demand, which can further regulate the voltage and frequency. Also, it can significantly improve the load availability, a key requirement for any power system. The energy storage, therefore, is a desired feature to incorporate with renewable power systems, particularly in stand alone power plants. The purpose of this book is twofold. At first, for the interested researcher it shows the importance of different Energy Storage devices, but secondly, and more importantly, it forms a first attempt at dissemination of knowledge to the wider non-expert community who may wish to consider Energy Storage device for specific application. Thus this book will be helpful to provide an indication of the tools necessary for an assessment to be made Energy Storage device more powerful.

\title{
How to reference
}

In order to correctly reference this scholarly work, feel free to copy and paste the following:

Rosario Carbone (2010). Energy Storage in Grid-Connected Photovoltaic Plants, Energy Storage, Rafiqul Islam Sheikh (Ed.), ISBN: 978-953-307-119-0, InTech, Available from:

http://www.intechopen.com/books/energy-storage/energy-storage-in-grid-connected-photovoltaic-plants

\section{INTECH}

open science | open minds

\section{InTech Europe}

University Campus STeP Ri

Slavka Krautzeka 83/A

51000 Rijeka, Croatia

\section{InTech China}

Unit 405, Office Block, Hotel Equatorial Shanghai

No.65, Yan An Road (West), Shanghai, 200040, China

中国上海市延安西路65号上海国际贵都大饭店办公楼405单元 
Phone: +385 (51) 770447

Fax: +385 (51) 686166

www.intechopen.com
Phone: +86-21-62489820

Fax: +86-21-62489821 
(C) 2010 The Author(s). Licensee IntechOpen. This chapter is distributed under the terms of the Creative Commons Attribution-NonCommercialShareAlike-3.0 License, which permits use, distribution and reproduction for non-commercial purposes, provided the original is properly cited and derivative works building on this content are distributed under the same license. 